\title{
Study of effectiveness of enrofloxacin and mox- ifloxacin in experimental salmonellosis of chickens
}

\author{
Vladimir Skvortsov*, Dmitry Yurin, Julia Tarasova, Andrey Kapustin, and Alexey \\ Laishevtsev \\ Federal State Budget Scientific Institution "Federal Scientific Centre VIEV” (FSC VIEV), 117218, \\ Moscow, Russia
}

\begin{abstract}
In this publication we present a comparative study of effectiveness of enrofloxacin and moxifloxacin for treatment of chickens, experimentally infected with Salmonella infantis. The chickens received both drugs in water-soluble form via drinking water ad libitum at concentrations of $200 \mathrm{mg} / \mathrm{L}, 100 \mathrm{mg} / \mathrm{L}, 50 \mathrm{mg} / \mathrm{L}$ and $25 \mathrm{mg} / \mathrm{L}$ one day before the challenge and then four consecutive days. The chickens were challenged by intraperitoneal injection with 150 million CFUs of one-day old agar culture of $S$. infantis in $0.5 \mathrm{~mL}$ isotonic saline. The observation period was 15 days. Enrofloxacin proved most effective (88\% and $84 \%$ ) at concentrations of $200 \mathrm{mg} / \mathrm{L}$ and $100 \mathrm{mg} / \mathrm{L}$. Lower concentrations caused a decrease in its effectiveness. When enrofloxacin was administered at a concentration of $50 \mathrm{mg} / \mathrm{L}$ the survival rate for chickens was $64 \%$. The effectiveness of moxifloxacin in our experiment was considerably lower. The survival rate for chickens, receiving moxifloxacin at concentrations $200 \mathrm{mg} / \mathrm{L}, 100 \mathrm{mg} / \mathrm{L}$, $50 \mathrm{mg} / \mathrm{L}$ and $25 \mathrm{mg} / \mathrm{L}$ was respectively $32 \%, 28 \%, 32 \%$ and $16 \%$, and their average lifespan was half as long as of those groups, receiving enrofloxacin. The results of our research prove the high effectiveness of enrofloxacin at a concentration $200 \mathrm{mg} / \mathrm{L}$ in drinking water for the treatment of experimental salmonellosis in chickens.
\end{abstract}

Keywords: endofloxacin, moxifloxacin, salmonellosis, chicken

\section{Introduction}

Bacteria of the genus Salmonella belong to the family Enterobacteriaceae. The Salmonella genus includes over 2,570 different serotypes. All species of this genus are pathogenic to animals and cause different types of illnesses. The ubiquity of Salmonella and its prevalence in the natural environment, on farms and in the food chain, as well as its adaptability to many animal reservoirs and routes of transmission, makes epidemiological studies of these bacteria very complex. Research into etiology of salmonellosis in poultry and improvement in methods of treating this disease are of great practical importance. The most common cause of Salmonella infection in humans all over the world is the so-called nontyphoidal Salmonella (NTS), which infects people via food made out of animal husbandry products $[1,2]$. In most cases salmonellosis is associated with serovars Salmonella enteritidis and Salmonella typhimurium of Salmonella enterica [3, 4]. Such is the case in Russia

*Corresponding author: skvn59@yandex.ru 
too. But after border control loosened and all kinds of livestock products and breeding livestock in large quantities were brought from other countries the number of isolated Salmonella serovars increased significantly. The biggest portion of them is represented by Salmonella infantis [5]. Salmonella infantis is one of the five serovars most frequently causing human salmonellosis in Europe, mainly associated with poultry. A clone harbouring a conjugative plasmid of emerging Salmonella infantis (pESI)-like megaplasmid, carrying multidrug resistant and extended-spectrum beta-lactamases enes, has spread in the chicken industry also causing human illness [6].

One of the most effective measures against salmonellosis in poultry today is rational employment of fluoroquinolone antimicrobials. Reports of previously performed research show their high antimicrobial activity in vitro [7], Salmonella dublin and Salmonella typhimurium showed the highest susceptibility to Enrofloxacin (100\%), Salmonella enteritidis and Salmonella choleraesuis proved a bit less susceptibility (95\% and 94,7\%), 5\% of Salmonella enteritidis isolates and 5,3\% of Salmonella choleraesuis isolates had intermediate susceptibility [8], the data of acute toxicity evaluated by the Litchfield-Wilcoxon method found that Enrofloxacin p.o. in chickens belongs to Category 3 of toxic substances [9, $10]$ and high effectiveness for treating unhealthy animals [11, 12], there are also reports of some fluoroquinolones increasing the phagocytic activity of leukocytes in poultry [13]. A more detailed study of possible effect of such fluoroquinolone as Enrofloxacin on bird immune system revealed the fact that this drug evidently promotes the phagocytic reaction. These are important findings telling about the absence of suppressive effect of Enrofloxacin on the process of innate immune response of poultry. The analysis of the received data suggests that Enrofloxacin has some impact on the function of phagocytic system cells of poultry, which was confirmed by increases of practically all indicators of phagocytic activity. Moreover looking at such increases in recovered values researchers can assume that Enrofloxacin is capable of exerting some immunostimulating effect. Researchers discovered reliable undulating shifts in some parameters, which could be caused by administration of Enrofloxacin but they could also depend on age of the chickens and their still developing immunity $[14,15,16]$. There are quite a few fluoroquinolones for veterinary use on the market today, including those of the fourth generation, such as moxifloxacin. But available publications on ways of its usage are incomplete and fragmentary. In the present publication we share the results of our research into effectiveness of two fluoroquinolone drugs, namely enrofloxacin and moxifloxacin, for treating chickens, experimentally infected with S. infantis.

\section{Materials and methods}

The experiment was carried out using the model for pre-clinical research of antimicrobials in treating experimentally infected susceptible animals [17]. In our research we used dayold male chicks (Hisex Brown cross), which we divided into groups of 25 chicks, using the method of analogous groups. For the experiment we also used a control groups and a group of intact chicks. All of these the chickens received properly balanced ration with basic nutrients and dietary supplements.

The inoculum (150 million CFUs Salmonella infantis) was prepared aseptically out of 24-h. old agar culture in $0.5 \mathrm{~mL}$ isotonic saline and then every chicken was challenged by intraperitoneal introduction. In the experiment we used commercially available enrofloxacin and moxifloxacin, ready for administration p.o. in drinking water. The drugs were administered 5 days, the first administration was performed 24 hours before the challenge.

Enrofloxacin and moxifloxacin were administered via drinking water at concentrations $200 \mathrm{mg} / \mathrm{L}, 100 \mathrm{mg} / \mathrm{L}, 50 \mathrm{mg} / \mathrm{L}$ and $25 \mathrm{mg} / \mathrm{L}$ (Table 1). 
The chickens were observed for 15 days. The indicators to assess the effectiveness of used drugs at given concentrations were average lifespan of chickens throughout the experiment and survivability of the flock in experimental and control groups [6]. The statistical reliability of the obtained data was checked with generally accepted methods.

\section{Results and Discussion}

As can be seen from the obtained data the culture of $S$. infantis, used to challenge the chickens, appeared quite virulent (Table 1). Accordingly, the mortality in the control group was $100 \%$, the average lifespan was $0,96 \pm 0,19$ days. Most of the chickens perished within 2 days following the challenge.

Investigation of medioprophylactic action of enrofloxacin in respect to experimental infection of chickens with $S$. infantis showed that this drug is most effective at concentrations $200 \mathrm{mg} / \mathrm{L}$ and $100 \mathrm{mg} / \mathrm{L}$. Thus enrofloxacin in drinking water at $200 \mathrm{mg} / \mathrm{L}$ ensured the survival rate of $88 \%$, while their average lifespan was $13,3 \pm 0,93$ days. But enrofloxacin in drinking water at $100 \mathrm{mg} / \mathrm{L}$ only ensured the survival rate of $84 \%$, and the average lifespan of chickens was $12,6 \pm 1,1$ days.

Survival rate for chickens, receiving enrofloxacin in drinking water at $50 \mathrm{mg} / \mathrm{L}$ was

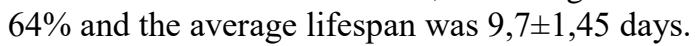

Enrofloxacin in drinking water was least effective at concentration $25 \mathrm{mg} / \mathrm{L}$. The mortality rate in this group of chickens was $92 \%$ and the average lifespan was just $1,4 \pm 0,82$ days.

Analysis of the response to treatment with moxifloxacin showed its low therapeutic effectiveness as regards treatment of chickens, experimentally infected with $S$. infantis.

Thus the survival rate in the group, receiving moxifloxacin at concentration $200 \mathrm{mg} / \mathrm{L}$, was as low as $32 \%$. The average lifespan in that experiment was $6,4 \pm 1,26$ days.

When the concentration became as low as $100 \mathrm{mg} / \mathrm{L}$, the survival rate dropped to $28 \%$ and the average lifespan dropped to $5,1 \pm 1,3$ days.

Table 1. Effectiveness of drugs in treating chickens for experimental salmonellosis

\begin{tabular}{|c|c|c|c|c|c|c|c|}
\hline \multirow[t]{2}{*}{ № } & \multirow[t]{2}{*}{ Drug } & \multirow[t]{2}{*}{$\begin{array}{c}\text { Number of } \\
\text { chickens }\end{array}$} & \multicolumn{2}{|c|}{$\begin{array}{c}\text { Number of chickens } \\
\text { survived }\end{array}$} & \multicolumn{2}{|c|}{$\begin{array}{l}\text { Number of chick- } \\
\text { ens perished }\end{array}$} & \multirow{2}{*}{$\begin{array}{c}\text { Average } \\
\text { lifespan of } \\
\text { chickens, } \\
\text { days } \\
\end{array}$} \\
\hline & & & head & $\%$ & head & $\%$ & \\
\hline 1 & $\begin{array}{c}\text { Enrofloxacin, } \\
200 \mathrm{mg} / \mathrm{L}\end{array}$ & 25 & 22 & 88 & $23(3)$ & 12 & $13,3 \pm 0,93$ \\
\hline 2 & / $100 \mathrm{mg} / \mathrm{L}$ & 25 & 21 & 84 & 4 & 16 & $12,6 \pm 1,1$ \\
\hline 3 & / 50 mg/L & 25 & 16 & 64 & $4(9)$ & 36 & $9,7 \pm 1,45$ \\
\hline 4 & / $25 \mathrm{mg} / \mathrm{L}$ & 25 & 2 & 8 & 23 & 92 & $1,4 \pm 0,82$ \\
\hline 5 & $\begin{array}{l}\text { Moxifloxacin, } \\
200 \mathrm{mg} / \mathrm{L}\end{array}$ & 25 & 8 & 32 & 17 & 68 & $6,4 \pm 1,26$ \\
\hline 6 & / $100 \mathrm{mg} / \mathrm{L}$ & 25 & 7 & 28 & 18 & 72 & $5,1 \pm 1,3$ \\
\hline 7 & ル $50 \mathrm{mg} / \mathrm{L}$ & 25 & 8 & 32 & 17 & 68 & $5,0 \pm 1,4$ \\
\hline 8 & / $25 \mathrm{mg} / \mathrm{L}$ & 25 & 4 & 16 & 21 & 84 & $4,2 \pm 1,17$ \\
\hline 9 & Control group & 25 & - & - & 25 & 100 & $0,96 \pm 0,19$ \\
\hline 10 & Intact group & 25 & 25 & 100 & - & - & 15,0 \\
\hline
\end{tabular}


In the groups, receiving moxifloxacin at concentrations $50 \mathrm{mg} / \mathrm{L}$ and $25 \mathrm{mg} / \mathrm{L}$, the survival rate was $32 \%$ and $16 \%$, their average lifespan was $5,0 \pm 1,4$ and $4,2 \pm 1,17$ days, respectively.

Observation of chickens in the intact group in the course of the experiment did not show any divergence or deviations in their state and development.

\section{Conclusion}

The experiment proved high effectiveness of enrofloxacin, when administered at concentration $200 \mathrm{mg} / \mathrm{L}$, for treatment of experimental salmonellosis in chickens. Prescription of enrofloxacin for 5 days ensured the survival rate $88 \%$ for chickens, experimentally infected with $S$. infantis. These results are to a great degree in correspondence with previously published reports $[2,8]$.

The analysis of the experiment results shows low effectiveness of moxifloxacin for treatment of chickens, experimentally infected with $S$. infantis, since the survival rate for the flock was $32 \%$ at best.

\section{References}

1. O. Gal-Mor, L. Valinsky, M. Weinberger, S. Guy, J. Jaffe, Y. Schorr, A. Raisfeld, V. Agmon, I. Nissan Israel Emerging Infectious Diseases, 16 (2010)

2. N. Nogrady, G. Kardos, A. Bistyak, I. Turcsanyi, J. Meszaros, Z. Galantai Int J Food Microbiol., 127 (2008)

3. H. Sato, M. Kawase J. Japan Veter. Med. Assn, 69 (2016)

4. R.V. Tauxe Emerging infections, 4 (1999)

5. S.V. Mezentsev Veterinary Medicine, 6 (2015)

6. P. Alba, P. Leekitcharoenphon, V. Carfora, R. Amoruso, G. Cordaro, P. Di Matteo, A. Ianzano, M. Iurescia, E.L. Diaconu, S.K. Pedersen, B. Guerra, R.S. Hendriksen, A. Franco, A. Battisti Microb Genom ,6(5) (2020)

7. E.V. Glebova, O.V. Maiboroda Actual Questions of Veterinary Biology 2 (2014)

8. D.V. Yurin, V.V. Nevzorova, A.A. Balbutskaya, S.S. Belimova International bulletin of Veterinary Medicine, 2 (2020)

9. D.V. Yurin, V.N. Skvortsov, V.V. Nevzorova [et al.] Actual issues in agricultural biology 4 (2020)

10. D.V. Yurin, V.N. Skvortsov, A.A. Prisnyi, A.A. Moiseeva Actual issues in agricultural biology, 4 (2019)

11. V.N. Skvortsov, D.V. Yurin, V.V. Nevzorova, A.D. Mazur International bulletin of Veterinary Medicine, 2 (2020)

12. A.A. Moiseeva, A.A. Prisnyi Issues of Legal Regulation in Veterinary Medicine, $\mathbf{1}$ (2020)

13. A.A. Moiseeva, A.A. Prisnyi, V.N. Skvortsov International bulletin of Veterinary Medicine, 1 (2020)

14. A.A. Moiseeva, A.A. Prisnyi, A.M. Gulyukin, T.V. Stepanova IOP Conference Series: Earth and Environmental Science, 548 (2020)

15. A.A. Prisnyi, A.A. Moiseeva, V.N. Skvortsov, V.V. Nevzorova IOP Conference Series: Earth and Environmental Science, 548 (2020) 
16. R.U. Khabriev Handbook of experimental (pre-clinical) study of new pharmacological substances (Medicine Publ., Moscow, 2005)

17. G.N. Pershin Methods in experimental chemotherapy (Medgiz Publ., Moscow, 1961) 